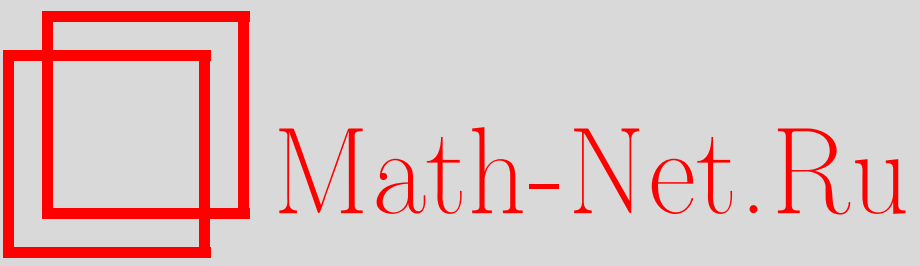

А. А. Голядкина, И. В. Кириллова, О. А. Щучкина, Анализ напряжённо-деформированного состояния и гемодинамики коронарных артерий и желудочков сердца человека, Вестн. Сам. гос. техн. ун-та. Сер. Физ.-мат. науки, 2011, выпуск 3(), 79-88

DOI: https://doi.org/10.14498/vsgtu989

Использование Общероссийского математического портала Math-Net.Ru подразумевает, что вы прочитали и согласны с пользовательским соглашением http://www.mathnet.ru/rus/agreement

Параметры загрузки:

IP : 3.82 .47 .9

26 апреля 2023 г., 15:12:25 


\title{
Биомеханика
}

\author{
УДК 539.3
}

\section{АНАЛИЗ НАПРЯЖЁННО-ДЕФОРМИРОВАННОГО СОСТОЯНИЯ И ГЕМОДИНАМИКИ КОРОНАРНЫХ АРТЕРИЙ И ЖЕЛУДОЧКОВ СЕРДЦА ЧЕЛОВЕКА}

\author{
А. А. Голядкина, И. В. Кириллова, О.А. Щучкина \\ Саратовский государственный университет им. Н. Г. Чернышевского, \\ 410012, Саратов, ул. Астраханская, 83. \\ E-mail: nano-bio@sgu.ru
}

Проведено исследование механических свойств коронарных артерий и тканей сердиа, компьютерное $3 D$-моделирование и численный анализ напряжённо-деформированного состояния и гемодинамики коронарных артерий и желудочков сердиа человека. Материал стенок артерий и тканей серди, предполагался линейным изотропным, кровъ-нъютоновской жидкостъю. Проведён сравнительный анализ полученных данных для случаев коронарных артерий, пространственно не закреплённых и закреплённых на пассивном миокарде, а также желудочков сердца в норме и при патологии.

Ключевые слова: левый (правый) желудочек, коронарные артерии, гемодинамика, напряжённо-дебормированное состояние, конечно-элементный расчёт, аневризма.

Введение. По данным Всемирной организации здравоохранения, основными причинами смертности населения являются заболевания сердечно-сосудистой системы - $64,5 \%$, из них более чем в $80 \%$ случаев причиной смерти является ишемическая болезнь сердца (ИБС) (http://www.who.int/en/). С этими данными согласуются данные о причинах смертности населения РФ (http://statistika.ru). Только совершенствование медицинской помощи населению, которое включает в себя расширение профилактических мероприятий, повышение качества диагностики и лечения за счёт повсеместного внедрения в практику ведения больных методов прогнозирования естественного течения заболевания и оптимизации как консервативных, так и оперативных способов лечения, разработку новых методов лечения, проведение комплексной реабилитации больных, позволит качественно изменить создавшуюся ситуацию. Комплексное решение данной проблемы возможно лишь с привлечением специалистов разных научных направлений. В частности, оценка напряжённо-деформированного состояния (НДС) тканей и расчёт гемодинамики артерий человека, проведённые на стадии предоперационного обследования пациента, позволят разработать оптимальный метод хирургического вмеша-

Голядкина Анастасия Александровна, аспирант, каф. математической теории упругости и биомеханики. Кириллова Ирина Васильевна (к.ф.-м.н., доц.), доцент, каф. математической теории упругости и биомеханики. Щучкина Ольга Александровна, аспирант, каф. математической теории упругости и биомеханики. 
тельства, дать рекомендации хирургу, как избежать возможных ошибок во время оперативного вмешательства.

1. Постановка задачи. Одной из основных причин ИБС (нарушение миокардиального кровообращения) является окклюзия и/или стеноз коронарных артерий (KA), по которым происходит снабжение кровью правого (ПЖ) и левого (ЛЖК) желудочков сердца. Следствием ИБС является инфаркт миокарда. Инфаркт миокарда, в особенности обширный трансмуральный, сопровождается изменениями геометрии, объёмов и массы миокарда ЛЖ. Для оценки степени эффективности хирургических вмешательств по реваскуляризации миокарда и восстановлению геометрии ЛЖ и сердца человека в целом, а также для оптимизации кровотока в системе КА, необходимо провести предварительное 3D-моделирование, рассматривая KA, желудочки сердца и взаимодействие между ними [1]. Ограниченные возможности проведения натурного эксперимента для изучения процессов гемодинамики в системе коронарных артерий и сократительной способности желудочков сердца человека заставили исследователей обратить свое внимание на возможности численного моделирования. Но из-за сложности моделирования и огромных вычислительных затрат большинство исследований, результаты которых опубликованы к настоящему времени, выполнены только для случаев упрощенных моделей КА с жёсткими $[2,3]$ и с податливыми $[4,5]$ стенками без учёта воздействия внешних сил на них. Работы, в которых предприняты попытки описать влияние сокращения и расслабления миокарда на систему КА, выполнены лишь для случая сильно упрощенной геометрии KA, когда в качестве артерии рассматривалась цилиндрическая трубка $[6,7]$. Группой исследователей под руководством F. Migliavacca [8,9] был проведён расчёт 3D-пульсирующего коронарного потока и определено давление в идеализированной модели КА [10]. В статьях $[11,12]$ представлены результаты исследований, направленных на получение граничных условий для трёхмерной модели кровотока отдельных частей ССС с использованием неявных методов. В более поздних публикациях [13-17] представлены результаты исследований взаимодействия сердца и части артериальной системы, результаты построения и расчётов НДС правого и левого желудочков сердца человека и взаимодействия между ними. Качество результатов численных экспериментов во многом зависит от соответствия математической и вычислительной моделей реальным физическим процессам, протекающим в системе «сердце - коронарные артерии».

Целью данной работы являлось моделирование поведения индивидуальных анатомически реальных KА, пространственно не закрепленных и закрепленных на пассивном миокарде, а также желудочков сердца в норме и при патологии.

2. Материалы и методы. При построении индивидуальной компьютерной модели необходимо задавать реальные параметры материала. Следовательно, определение геометрии и механических свойств тканей является необходимым подготовительным этапом процесса моделирования. В данной работе в качестве примера представлены результаты исследования механических свойств аорты, легочной артерии (ЛА) и КА. Материалом для экспериментов послужили нефиксированные образцы тканей, изъятые у 46 трупов людей обоего пола в возрасте от 27 до 80 лет (см. табл. 1), поступивших в Саратовское городское бюро судебно-медицинской экспертизы (разрешение на за- 
Таблица 1

\section{Распределение исследованных трупов по полу, возрасту и причине смерти}

\begin{tabular}{|c|c|c|c|}
\hline № $\Pi / \Pi$ & Пол & Годы жизни & Причина смерти \\
\hline 1 & M & $1957-2009$ & Механическая асфиксия \\
\hline 2 & $\mathrm{M}$ & $1947-2009$ & Механическая асфиксия \\
\hline 3 & K & $1946-2009$ & Геморрагический инсульт \\
\hline 4 & $\mathrm{M}$ & $1961-2009$ & Механическая асфиксия \\
\hline 5 & M & 1937-2009 & Механическая асфиксия \\
\hline 6 & M & 1957-2009 & Отравление углекислым газом \\
\hline 7 & M & 1982-2009 & Пневмония \\
\hline 8 & M & 1980-2009 & Термический ожог \\
\hline 9 & $\mathrm{M}$ & $1963-2009$ & Механическая асфиксия \\
\hline 10 & $\mathrm{M}$ & $1963-2009$ & Геморрагический инсульт \\
\hline 11 & M & 1955-2009 & Тупая травма головы \\
\hline 12 & M & 1973-2009 & Механическая асфиксия \\
\hline 13 & KK & 1944-2009 & Цирроз печени \\
\hline 14 & K & $1956-2009$ & Кровотечение ЖКТ \\
\hline 15 & $\mathrm{M}$ & $1953-2009$ & Жировой гепатоз \\
\hline 16 & $\mathrm{M}$ & $1956-2009$ & Механическая асфиксия \\
\hline 17 & M & $1954-2009$ & Общее переохлаждение \\
\hline 18 & M & 1953-2009 & Геморрагический инсульт \\
\hline 19 & $\mathrm{M}$ & 1937-2009 & Внутреннее кровотечение \\
\hline 20 & $\mathrm{M}$ & $1961-2009$ & Геморрагический инсульт \\
\hline 21 & $\mathrm{M}$ & $1955-2009$ & Общее переохлаждение \\
\hline 22 & $\mathrm{M}$ & $1962-2009$ & Отравление этиловым спиртом \\
\hline 23 & $\mathrm{M}$ & $1964-2009$ & Отравление этиловым спиртом \\
\hline 24 & M & 1929-2009 & Цирроз печени \\
\hline 25 & $\mathrm{M}$ & $1978-2009$ & ДТП (тупая травма тела) \\
\hline 26 & $\mathrm{M}$ & $1948-2009$ & Механическая асфиксия \\
\hline 27 & M & $1976-2009$ & Отравление этиловым спиртом \\
\hline 28 & $\mathrm{M}$ & $1970-2009$ & Отравление углекислым газом \\
\hline 29 & $\mathrm{M}$ & $1945-2009$ & Механическая асфиксия \\
\hline 30 & M & 1947-2009 & Отравление этиловым спиртом \\
\hline 31 & M & $1954-2009$ & Общее переохлаждение организма \\
\hline 32 & $\mathrm{M}$ & 1939-2009 & Арозивный гастрит, кровотечение ЖККТ \\
\hline 33 & $\mathrm{M}$ & $1961-2009$ & Механическая асфиксия \\
\hline 34 & K & $1955-2011$ & Рак головного мозга \\
\hline 35 & $\mathrm{M}$ & $1934-2011$ & Отравление неизвестным веществом \\
\hline 36 & M & $1935-2011$ & Рак поджелудочной железы \\
\hline 37 & M & $1941-2011$ & Острый инфаркт миокарда \\
\hline 38 & $\mathrm{M}$ & $1938-2011$ & Новообразование предстательной железы \\
\hline 39 & $\mathrm{M}$ & $1952-2011$ & ТСТГ \\
\hline 40 & K & $1956-2011$ & Отравление уксусной кислотой \\
\hline 41 & $\mathrm{M}$ & $1946-2011$ & Отравление неизвестным вешеством \\
\hline 42 & $\mathrm{M}$ & $1989-2011$ & Утопление \\
\hline 43 & M & $1971-2011$ & Острое кровотечение \\
\hline 44 & $\mathrm{M}$ & $1952-2011$ & Утопление \\
\hline 45 & $\mathrm{M}$ & $1959-2011$ & Пневмония \\
\hline 46 & M & $1946-2011$ & Механическая асфиксия \\
\hline
\end{tabular}


бор образцов давалось этической комиссией). Препарирование проводилось на кафедре оперативной хирургии и топографической анатомии ГОУ ВПО «Саратовский государственный медицинский университет им. В. И. Разумовского».

Исследования проводились на одноосной разрывной машине Instron с использованием BioBath на нефиксированных образцах тканей. Использование BioBath позволяет проводить испытания в жидкой среде, что значительно повышает точность результатов. Испытания проводились не позднее первых суток после смерти, пока не произошло значимых изменений морфологических характеристик тканей и полученные данные могут быть экстраполированы на живого человека. Все материалы были распределены по трём возрастным группам: I группа - 1937-1950 г.p., II группа - 1951-1970 г.p., III группа 1970-1982 г.р.

Изучение образцов КА по сегментам позволило выявить зависимость между номером сегмента (его удаленностью от основной ветви артерии) и эластичностью артерии: чем дальше сегмент от основной ветви артерии, тем меньшей эластичностью он обладает (см. табл. 2). Следует обратить внимание на разброс данных в I возрастной группе, т.к. при поражении тканей сердца мелкоочаговым и крупноочаговым кардиосклерозом образцы демонстрируют меньшую эластичность, нежели не пораженные (см. табл. 3).

Для реконструкции сердца человека, учитывающей внутренний рельеф, применялся метод заливки желатином in vitro с дальнейшей обработкой результатов посредством графических редакторов Adobe Photoshop и CorelDraw. На базе данных морфометрии, предложенных в руководстве для врачей $[18$, 19], с использованием специализированного программного пакета SolidWorks 2008 (SolidWorks corporation) было проведено построение 3D-модели желудочков, сердца в целом и модели КА (рис. 1).

Таблица 2

Значения модуля Юнга (МПа) КА

\begin{tabular}{l|c|c|c}
\hline Тип сегмента & I группа & II группа & III группа \\
\hline \multicolumn{4}{c}{ Левая КА } \\
\hline Основной ствол & $6,1-15,7$ & $4,4-6,6$ & $3,4-4,5$ \\
Огибающая ветвь & $9,3-12,7$ & $5,9-9,3$ & $5,3-6,4$ \\
Ветвь тупого края & $8,1-8,7$ & $3,9-5,9$ & $3,4-5,3$ \\
Диагональная ветвь & $4,2-5,2$ & $4,1-4,7$ & $4,1-4,5$ \\
Передняя нисходящая ветвь & $4,4-15,2$ & $6,2-12,4$ & $4,5-6,2$ \\
\hline \multicolumn{4}{c}{ Правая КА } \\
\hline Основной ствол & $5,2-23,8$ & $9,2-14,8$ & $3,2-4,1$ \\
Правая межжелудочковая ветвь & $5,8-9,7$ & $4,9-5,6$ & $3,5-4,3$ \\
Задняя межжелудочковая ветвь & $5,1-9,7$ & $5,8-8,7$ & $4,1-5,3$ \\
\hline
\end{tabular}

Таблица 3

Значения модуля Юнга (МПа) ЛА и аорты

\begin{tabular}{c|c|c|c|c|c|c}
\hline Тип & \multicolumn{2}{|c|}{ Продольное направление } & \multicolumn{3}{c}{ Поперечное направление } \\
\cline { 2 - 7 } материала & I группа & II группа & III группа & I группа & II группа & III группа \\
\hline Аорта & $2,8-5,9$ & $3,4-3,9$ & $2,8-3,1$ & $3,4-5,4$ & $4,0-5,1$ & $2,9-4,0$ \\
ЛА & $3,0-7,8$ & $4,1-5,3$ & $4,3-4,6$ & $2,7-9,0$ & $3,7-4,4$ & $3,1-3,8$ \\
\hline
\end{tabular}




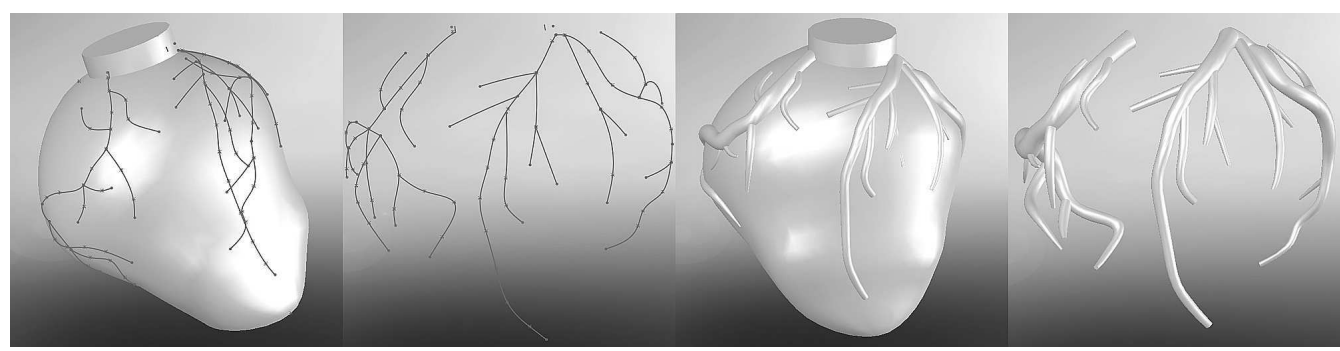

Рис. 1. Этапы построения пространственной 3D-геометрии KA

3. Математическое моделирование. Для изучения НДС и гемодинамики KA и сердца человека 3D-модели были импортированы в ANSYS Multiphysics (рис. 2).

При моделировании динамики кровотока и НДС стенок КА кровь предполагалась однородной, несжимаемой и ньютоновской жидкостью. Движение крови описывалось следующей системой уравнений:

$$
\rho_{1} \frac{\partial u_{1}}{\partial t}-\nabla \cdot\left[-p I+\eta\left(\nabla \overrightarrow{u_{1}}+\left(\nabla \overrightarrow{u_{1}}\right)^{\top}\right)\right]+\rho_{1}\left(\overrightarrow{u_{1}} \cdot \nabla\right) \overrightarrow{u_{1}}=0, \quad-\nabla \overrightarrow{u_{1}}=0,
$$

где $\overrightarrow{u_{1}}\left(u_{1}, v_{1}, w_{1}\right)$ - вектор скорости крови, $p$ - давление крови, $I$ - единичная матрица, $\rho_{1}$ - плотность жидкости, $\eta$ - динамический коэффициент вязкости жидкости.

Материал стенок предполагался однородным, изотропным, идеально-упругим.

Движение стенки в нестационарном случае описывалось вторым законом Ньютона:

$$
\rho_{2} \frac{\partial^{2} \vec{u}}{\partial t^{2}}-\nabla \cdot c \nabla \vec{u}=\vec{F}
$$

где $F$ - вектор внешних сил, $\vec{u}(u, v, w)$ - вектор перемещения, $c$ - константа, $\rho_{2}$ - плотность стенки.

Граничные условия на стенке задавались в виде

$$
F_{T}=-\vec{n}\left(-p I+\eta\left(\nabla \overrightarrow{u_{1}}+\left(\nabla \overrightarrow{u_{1}}\right)^{\top}\right)\right),
$$

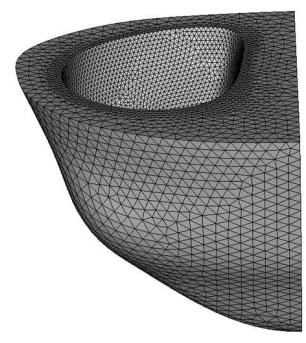

a

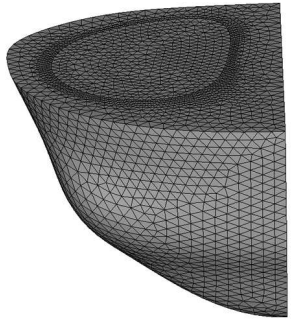

б

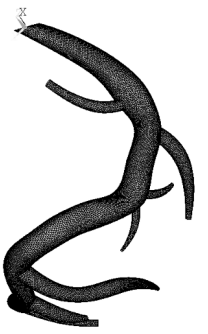

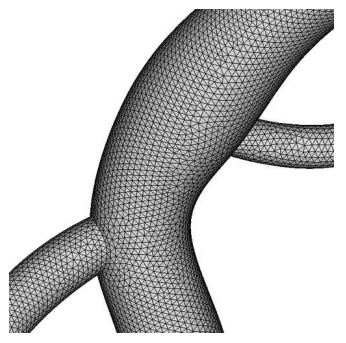

Рис. 2. Наложение расчётной сетки на модель стенки ЛЖ (а), модель ЛЖ (б), модель правой KА (в), нерегулярные тетраэдрические элементы сетки правой КА (г) 
где $n$-вектор внешней нормали к границе. Сила представляет собой суммарное воздействие давления и сил вязкости на стенку. Торцы сосуда жёстко закреплены.

На стенке артерии ставилось условие равенства скоростей частиц жидкости, прилегающих к стенке, и соответствующих частиц стенки:

$$
u_{1}=\frac{\partial u}{\partial t}, \quad v_{1}=\frac{\partial v}{\partial t}, \quad w_{1}=\frac{\partial w}{\partial t} .
$$

На входе в артерию задавалась скорость течения крови, изменяющаяся по физиологическому закону. На выходе - постоянное давление.

Механические характеристики крови, стенки артерии, тканей сердца следующие: $\rho_{1}=1050 \mathrm{\kappa г} / \mathrm{m}^{3}, \eta=0,0037 \Pi а \cdot \mathrm{c}, \rho_{2}=1378 \mathrm{\kappa г} / \mathrm{m}^{3}, E=6 \cdot 10^{5} \mathrm{H} / \mathrm{m}^{2}$ (модуль Юнга для КА), $E=2 \cdot 10^{7} \mathrm{H} / \mathrm{m}^{2}$ (модуль Юнга миокарда).

4. Результаты расчётов. Анализ НДС и гемодинамики артерий человека позволяет оценить степень эффективности соответствующих хирургических вмешательств по восстановлению кровообращения и разработать оптимальный метод хирургического вмешательства. При рассмотрении задачи коронарного кровообращения необходимо учитывать, что коронарный кровоток осуществляется под влиянием работы сердечной мышцы. В процессе решения должно рассматриваться взаимное влияние КА и сердечной мышцы, а также желудочков сердца.

Проведён расчёт двух случаев: в первом случае рассматривалось поведение пространственно не закрепленной коронарной артерии, во второмкоронарной артерии, закреплённой на миокарде.

В ходе эксперимента были получены следующие результаты в заданном сечении:

- в районе изгиба артерии локальное давление крови минимально на внутренней стенке изгиба, а по мере приближения к наружной стенке увеличивается и достигает максимума на самой стенке. Для пространственно не закреплённой модели наблюдается плавное распределение локального давления; в случае модели, учитывающей взаимодействие КА и миокарда, - контрастное;

- для скорости потока крови характерна зависимость, обратная давлению, максимальные значения достигаются у внутреннего радиуса в районе изгиба артерии; для модели КА с закреплением на миокарде наблюдается локальное смещение к внутреннему радиусу изгиба (рис. 3);

- за счёт разницы давления (у наружного и внутреннего радиусов) возникают потоки поперечной циркуляции, имеющие характер завихрения как в зоне бифуркации, так и в зонах перегиба; в районе перегибов наблюдаются низкие касательные напряжения;

- максимальные значения вектора перемещений узлов элементов достигаются на внешнем радиусе в районе перегиба артерии для пространственно не закрепленной модели; для модели, закрепленной на миокарде, максимальные значения достигаются на незакрепленной стенке (рис. 4).

При инфаркте миокарда происходит архитектурная перестройка желудочков сердца, особенно ЛЖ, что серьёзно влияет на их функциональную способность и прогноз течения заболевания. При проведении численного эксперимента по определению НДС и гемодинамики желудочков сердца были 

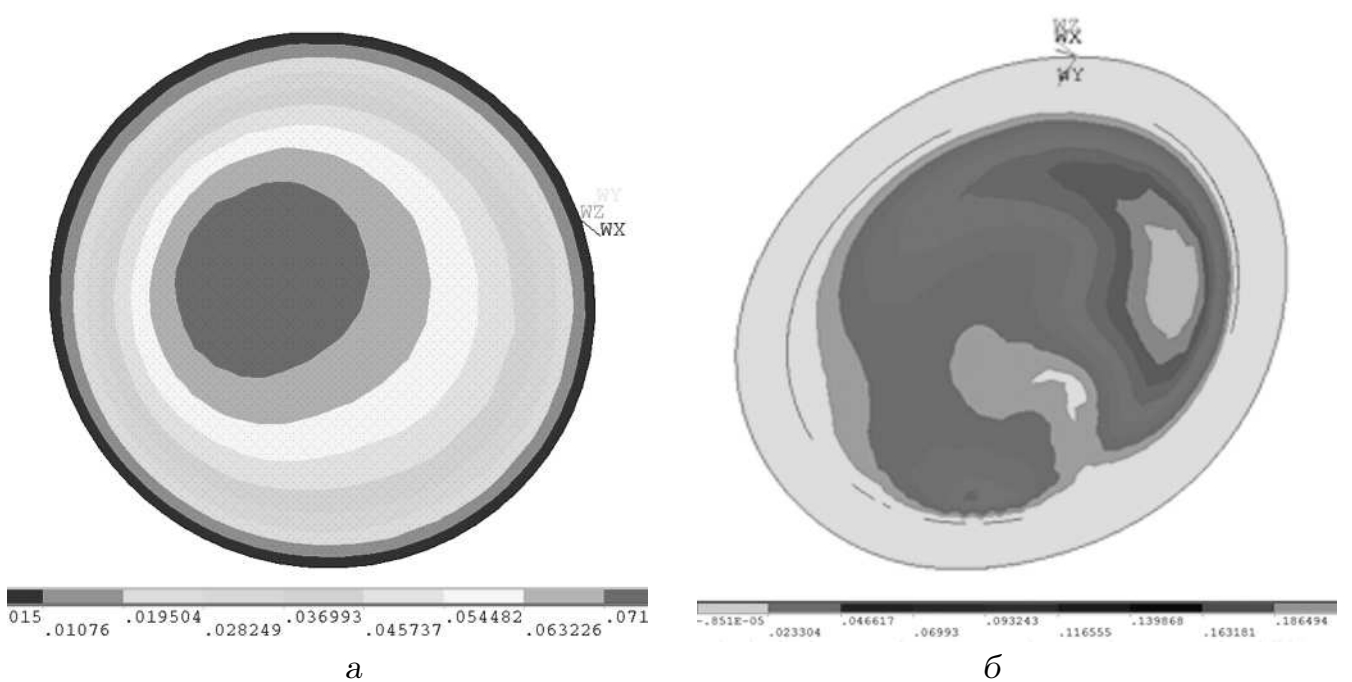

Рис. 3. Распределение значений скорости потока: а) пространственно незакреплённая КА, б) $\mathrm{KA}$, закреплённая на миокарде

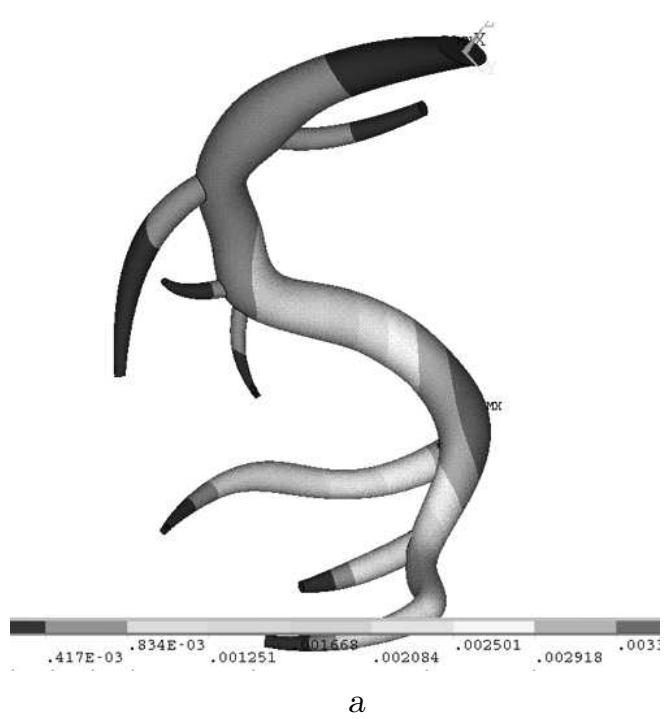

a
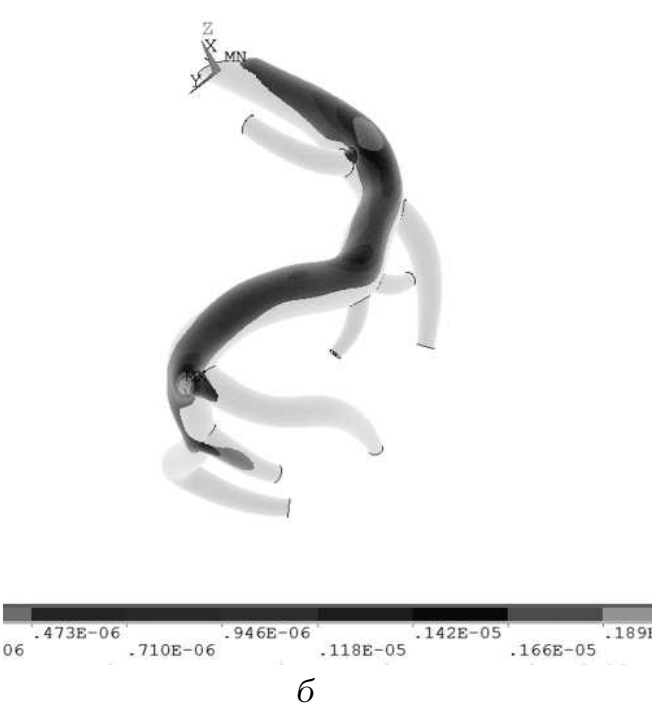

Рис. 4. Деформации: а) пространственно незакреплённая KA, б) KA, закреплённая на миокарде 
рассмотрены модели ЛЖ в норме, ЛЖ с патологией (аневризма), а также модель, позволяющая оценить характер взаимодействия между ПЖ и ЛЖ. Численное исследование ЛЖ в норме показало, что за счёт разницы давления (рис. 5, а) возникают потоки поперечной циркуляции, имеющие характер завихрения в предсердно-желудочковой зоне. При рассмотрении ЛЖ с патологией (аневризма) были получены следующие результаты:

1) за счёт уменьшения воздействия стенки на поток смещается поле давления (рис. 5, б);

2) максимальное давление в начале и в конце систолы достигается в ампуле аневризмы;

3) за счёт разницы давления на внутренней и внешней стенках ЛЖ наблюдаются потоки поперечной циркуляции, имеющие характер завихрения в основании ЛЖ.

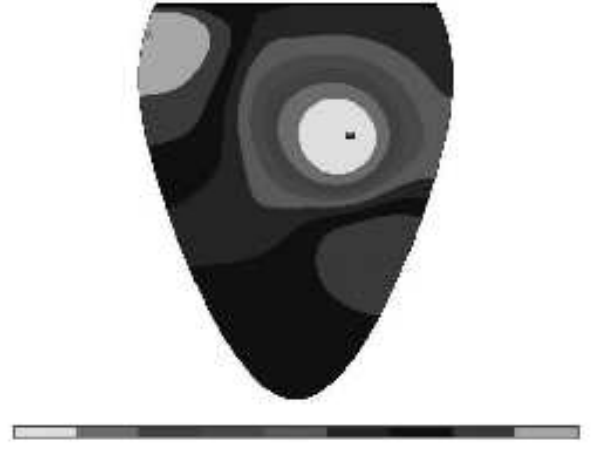

a

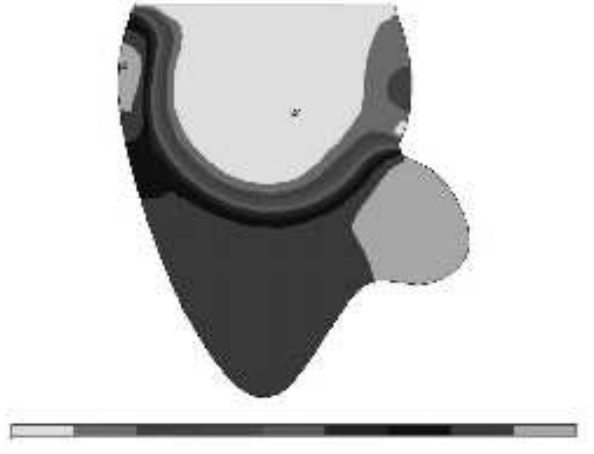

$\sigma$

Рис. 5. Распределение давления в ЛЖ: а) норма, б) патология

При анализе НДС камер желудочков сердца с жёстким закреплением межжелудочковой перегородки было зафиксировано, что большей активностью (при равной сократительной функциональности стенки) обладает левый желудочек. Полученные данные подтверждены клинически.

Выводы. В данной работе представлены результаты численного исследования НДС и гемодинамики коронарных артерий, пространственно не закреплённых и закреплённых на миокарде, а также желудочков сердца в норме и при патологии.

Полученные результаты подтвердили необходимость моделирования коронарного кровотока с учётом действия на него сердечной мышцы, так как в отличие от потока в других частях артериальной системы коронарный поток осуществляется под действием внутримиокардиального давления, что увеличивает внесосудистое сжатие.

В результате моделирования были получены параметры, которые будут использованы для проведения виртуальных операций как по восстановлению нормальной гемодинамики в КА, так и по восстановлению различными типами заплат анатомически здоровой геометрии ЛЖ.

Работа выполнена при поддержке РФФИ (проект № 09-01-00804-а). 


\section{БИБЛИОГРАФИЧЕСКИЙ СПИСОК}

1. Opie L. H. Heart Physiology: from cell to circulation. Philadelphia: Lippincott, Williams \& Wilkins, 2003. 648 pp.

2. Berry J. L., Santamarina A., Moore J. E., Roychowdhury S., Routh W. D. Experimental and Computational Flow Evaluation of Coronary Stents // Ann. Biomed. Eng., 2000. Vol.28, no. 4. Pp. 386-398.

3. Gijsen F.J.H., Wentzel J.J., Thury A., Mastik F., Schaar J.A., Schuurbiers J.C.H., Slager C. J., van der Giessen W. J., de Feyter P. J., van der Steen A.F. W., Serruys P.W. Strain distribution over plaques in human coronary arteries relates to shear stress // Am. J. Physiol. Heart Circ. Physiol., 2008. Vol. 295, no. 4. Pp. 1608-1614.

4. Qiu Y., Tarbell J. M. Numerical Simulation of Pulsatile Flow in a Compliant Curved Tube Model of a Coronary Arter // J. Biomech. Eng., 2000. Vol.122, no. 1, 77. 9 pp.

5. Zeng D., Boutsianis E., Ammann M., Boomsma K., Wildermuth S., Poulikakos D. A Study on the Compliance of a Right Coronary Artery and Its Impact on Wall Shear Stress // J. Biomech. Eng., 2008. Vol. 130, no. 4, 041014. 11 pp.

6. Ramaswamy S.D., Vigmostad S. C., Wahle A., Lai Y.-G., Olszewski M.E., Braddy K.C., Brennan T.M.H., Rossen J.D., Sonka M., Chandran K.B. Fluid Dynamic Analysis in a Human Left Anterior Descending Coronary Artery with Arterial Motion // Ann. Biomed. Eng., 2004. Vol. 32, no. 12. Pp. 1628-1641.

7. Santamarina A., Weydahl E., Siegel J. M., Moore J. E. Computational Analysis of Flow in a Curved Tube Model of the Coronary Arteries: Effects of Time-varying Curvature // Ann. Biomed. Eng., 1998. Vol. 26, no. 6. Pp. 944-954.

8. Migliavacca F., Balossino R., Pennati G., Dubini G., Hsia T. Y., de Leval M. R., Bove E. L. Multiscale modelling in biofluidynamics: Application to reconstructive paediatric cardiac surgery // J. Biomech., 2006. Vol. 39, no. 6. Pp. 1010-1020.

9. Lagana K., Balossino R., Migliavacca F., Pennati G., Bove E. L., de Leval M. R., Dubini G. Multiscale modeling of the cardiovascular system: application to the study of pulmonary and coronary perfusions in the univentricular circulation // J. Biomech, 2005. Vol. 38, no. 5. Pp. 1129-1141.

10. Kim H.J., Figueroa C.A., Hughes T.J.R., Jansen K.E., Taylor C.A. Augmented Lagrangian method for constraining the shape of velocity profiles at outlet boundaries for three-dimensional finite element simulations of blood flow // Comput. Methods Appl. Mech. Eng., 2009. Vol. 198, no. 45-46. Pp. 3551-3566.

11. Vignon-Clementel I.E., Figueroa C.A., Jansen K.E., Taylor C.A. Outflow boundary conditions for three-dimensional finite element modeling of blood flow and pressure in arteries // Comput. Methods Appl. Mech. Eng., 2006. Vol.195, no. 29-32. Pp. 3776-3796.

12. Vignon-Clementel I.E., Figueroa C.A., Jansen K.E., Taylor C.A. Outflow boundary conditions for 3D simulations of non-periodic blood flow and pressure fields in deformable arteries // Comput. Methods Biomech. Biomed. Eng., 2010. Vol. 13, no. 5. Pp. 625-640.

13. Kim H.J., Vignon-Clementel I.E., Figueroa C.A., LaDisa J.F., Jansen K.E., Feinstein J. A., Taylor C. A. On Coupling a Lumped Parameter Heart Model and a ThreeDimensional Finite Element Aorta Model// Ann. Biomed. Eng., 2009. Vol.37, no. 11. Pp. 2153-2169.

14. Göktepe S., Abilez O.J., Kuhl E. A generic approach towards finite growth with examples of athlete's heart, cardiac dilation, and cardiac wall thickening // J. Mech. Phys. Solids, 2010. Vol. 58, no. 10. Pp. 1661-1680.

15. Schwaiger M., Ziegler S.I., Nekolla S. G. PET/CT challenge for the non-invasive diagnosis of coronary artery disease // European Journal of Radiology, 2010. Vol.73, no. 3. Pp. 494503.

16. Sun A., Fan Y., Deng X. Numerical Study of Hemodynamics at Coronary Bifurcation with and without Swirling Flow / In: 6th World Congress of Biomechanics (August 1-6, 2010, Singapore) / IFMBE Proceedings, 31, 2010. Pp. 1428-1430. 
17. Kim H. J., Vignon-Clementel I. E., Coogan J.S., Figueroa C. A., Jansen K. E., Taylor C. A. Patient-Specific Modeling of Blood Flow and Pressure in Human Coronary Arteries // Ann. Biomed. Eng., 2010. Vol. 38, no. 10. Pp. 3195-3209.

18. Островский Ю. П. Хирургия сердца: Руководство. М.: Мед. лит., 2007. 576 с. [Ostrovskiy Yu. P. Heart surgery: A guide. Moscow: Med. Lit., 2007. 576 pp.]

19. Авалиани В.М., Червов И.И., Шобнин А.Н. Коронарная хирургия при мультифокальном атеросклерозе. М.: Универсум, 2005. 384 с. [Avaliani V.M., Chervov I.I., Shobnin A. N. Coronary surgery with multifocal atherosclerosis. Moscow: Universum, 2005. 384 pp.]

Поступила в редакцию $02 / \mathrm{II} / 2011$;

в окончательном варианте - 02/VIII/2011.

MSC: 92C10, 74L15

\section{INVESTIGATION OF HUMAN CORONARY ARTERIES AND HEART VENTRICLES MODE OF DEFORMATION AND HAEMODYNAMICS}

\section{A. A. Golyadkina, I. V. Kirillova, O. A. Schuchkina}

Saratov State University named after N. G. Chernyshevsky, 83, Astrkhanskaya st., Saratov, 410012, Russia.

E-mail: nano-bio@sgu.ru

Mechanical properties of coronary arteries and heart tissues, computer $3 D$ models of $C A$ and heart ventricles were investigated. Numerical analysis of coronary arteries and heart ventricles mode of deformation and haemodynamics was made. The material of the arteries and heart tissue was assumed as linear isotropic, the blood as a Newtonian fluid. Comparative analysis of numerical data for cases of spatially unfixed coronary arteries and fixed coronary arteries of passive myocardium and for pathological and healthy heart ventricles was conducted.

Key words: left (right) ventricle, coronary arteries, haemodynamics, mode of deformation, finite-element analysis, aneurism.

Original article submitted 02/II/2011; revision submitted 02/VIII/2011.

Anastsia A. Golyadkina, Postgraduate Student, Dept. of Mathematical Theory of Elasticity \& Biomechanics. Irina V. Kirillova (Ph. D. (Phys. \& Math.)), Associate Professor, Dept. of Mathematical Theory of Elasticity \& Biomechanics. Olga A. Schuchkina, Postgraduate Student, Dept. of Mathematical Theory of Elasticity \& Biomechanics. 